\title{
Tittle: The Study of Frank Money's Chronic Trauma and Complex Post-traumatic Stress Disorder in Toni Morrison's Home
}

\author{
Suhair Fuaad AL- Duhoki \\ Department of English Language, College of Languages and Human Sciences, University of Garmian
}

\begin{abstract}
African American went through centuries of repeated cruelties, disgrace, and segregation, along with psychological domination leaving its influences and imprints on their personalities. Distorted personality, seemingly, has become an identical feature of the African American males; it stuck to their characters even after gaining literal freedom from slavery. The purpose of this study is to explore the traumatic experience of the African American male protagonist in an African American novel; Toni Morrison's, Home (2012). The study examines the impact of repeated form of trauma on male personality. Morrison typifies African American male's role and behavior in society and family -in the mid- 20th century. The main aim here is to expose the traumatic experience impacts on the protagonist, Frank, showing how it consequently affects the social constructed aspect of his personality. The analysis employs the concept of the complex post-traumatic stress disorder which is introduced fully in Judith Herman's book, Trauma and Recovery. Herman gives insights into the theory from psychological thinking relying on the studies of her own and of other previous researches in the field of psychological trauma. This study traces the origin of the existing misunderstanding caused by some African Americans' behaviours. Studying the novel and probing the impacts of chronic trauma on the character's personality clarifies and even justifies many social performances like violence and passivity. Moreover, African Americans trauma is not a single traumatic experience, but a chronic one. In effect, it is the male characters complex traumatic syndrome which defines their masculinity.
\end{abstract}

\section{Introduction}

Regardless of their emancipation from slavery in 1865, African Americans encountered discrimination in every aspect of their lives in America. After the Civil War, many blacks went to work with the ir former masters in order to provide food and life expenditure. However, what they gained was a share of crops which was not sufficient for paying rent and buying other supplies. In this way, they were pushed to be in debt all the time. There was a wide spread code since 1890s, like 'separate but equal', which enforced the blacks to use distinct public facilities like churches, schools, restaurants, hotels, bus seats, public toilets, bathrooms and water fountains. Of course, African Americans' separate services were usually and considerably second-rate compared with those provided for the whites. These second class, unemployed, and sometimes low-paid citizens lived the in poor and underprivileged districts. The litanies of abuses increased day by day besides lynching and using the blacks as human laboratory animals in medical experiments. Therefore, it is obvious that the abolishment of slavery did not end the trauma of African 
American people. The repeated abuses, humiliation and segregation that the African American passed through have their own influences and imprints on their personality. The black male was denied to act freely, being deprived of taking the role of an honorable, protector and provider father. He had to repress his anger, weep and grief for a long time tolerating the cries of his beloved family members as they were tortured. Distorted personality has become the standard factor an African American male took and was equipped with when he was given the chance to live as a free man.

Bell Hooks in We Real Cool (2005) states that "while social critics looking at black life have continually emphasized the notion that black men were symbolically castrated because black women were often the primary breadwinners" (8). She also holds the viewpoint that some studies and researches about black families done by white Americans confirm that blacks suffer from "disrupted marriage" and families are affected by their "lack of interest in sustaining two-parent households" (10). To find out the truth or the problems behind what have been said about black men in America, we need to go further to trace the impacts of their chronic trauma which, as it has been noticed, encapsulate a further issue besides the personality disorder.

In fact, most of the conditions that caused and nourished psychological trauma during 1930s1950s in America are presented in Toni Morrison's very recent novel Home (2012). Toni Morrison (1931) is one of the African American greatest authors who has determined her literary life on the trauma of African Americans in her novels. Through her chronicle novels, she explores the lives, societies, individuals, and histories of her people in America. Morrison's quests for discovering the roots of most destructive aspects of behaviour and personality might have its claim from her personal life as well. She brought up her sons alone and took their responsibility after her divorce from a six year marriage. She had to work more than one job to afford a comfortable life for her sons in the segregated America during the 1960s and 1970s. Thus, it is not strange to find the theme of the role of father, or man, in general reflected in most of her works. She published her first novel The Bluest Eyes in 1970. Since then she has written ten novels including Home (2012), her most recent one. As usual, in her fiction, Morrison exposes new forgotten facts about African Americans' daily life in America besides high lighting the neglected period in American history which is the Korean War in the 1950s. The most critical achievement in Morrison's novel, Home, is placed in her capability to portray what it denotes to be a black in America of the postbellum throughout the 1930s-1950s. The novel is set in a society where the black individuality is looked down and segregated in relation to the supreme whiteness and the touches of this inferiority advocate an array of trauma in connection to African American experiences. Home is about an African American war veteran, Frank, who has a disturbed childhood memory which combines with his struggles with the changes that have been happening to his psyche after his return from Korea. Frank's disorder continues in the segregated America who treats him less than an animal depriving him of any solace.

Reading Toni Morrison's Home, one can understand that the male character in the novel is suffering from social domination and oppression. Herman suggests that people in captivity, due to the social oppression and the abuse of prolonged repeated trauma, suffer from an established sever personality disorganization. Therefore, Herman's concept of chronic trauma is significant while dealing with the problems of personality disorder and role dysfunction. Thus, this study seeks to prove that the African American male character, Frank, is chronically traumatized 
individual; his trauma has not caused from a single traumatic experience. Hence, it is his prolonged repeated trauma that defines many aspects of his personality including his social role. In this study Home will be analyzed, where the elements of the male character's psychological domination will be discovered, and the syndrome of his chronic trauma or complex posttraumatic stress disorder will be examined.

It is essential first to define the term 'trauma' before tackling the concern of this paper. As it is known the traumatic event attacks without warning and reverses daily experiences effectively. A number of approaches have historically grown around the relations of trauma to psychoanalytic discourse and individual's identity development as well as the performances of well-being. Lenore Terr states that, "psychic trauma occurs when a sudden, unexpected, overwhelming intense emotional blow or a series of blows assaults the person from outside. Traumatic events are external, but they quickly become incorporated into the mind" (8). Cathy Caruth in her essay The Wound and the Voice illustrates that Freud called the traumatic event "traumatic neurosis" and defined it as disturbing event that is undesirable as well as uncontrollable and repeats itself persistently and unconsciously in the survivors' acts. This repetition of the traumatic experience appears to be due to the victim's inability to leave it behind. Caruth affirms that literature and psychoanalysis are both concerned in the multifaceted link between 'knowing' and unknowing. Accordingly, Frank's traumatic syndromes take the quality of knowing and unknowing due to the unjustifiable nature of his domination which prevents him normally assimilating his trauma into his everyday experience.

Cleo Van Velsen elaborates that the wound which is the root of trauma involves penetration and damage of the 'protective shield' whose essential function is to protect the ego (mind) from being intimidated by the internal and external stimuli. The link between the external and internal reality is the root of developing the concept of Post-traumatic Stress Disorder. The term post-traumatic stress disorder which is referred to by the abbreviation (PTSD) is provided by the American Psychiatric Association in the Diagnostic and Statistical Manual of Mental Disorders, the third edition (1980), to what had formerly been called shellshock, combat neurosis, or traumatic neurosis. In A Guide to Psychological Debriefing (2007), David Kinchin defines the official definition of Post-traumatic Stress Disorder as:

Post-Traumatic Stress Disorder results when a person has been exposed to an event which may be outside the range of normal human experience: an event which would markedly distress almost anyone. It is the normal human response to an abnormal situation (Kinchin, 12).

In fact he introduces the forces that may lead to traumatic experience including a serious lifethreatening event to a person or to the children, spouse, parents, relatives or friends. It can also be the unexpected destruction of a person's home or community, witnessing others abuse, and rape. Furthermore, he argues that people react to traumatic events differently as it is not a condition to have the same symptoms or reactions to the identical event. The individual's reaction to the traumatic situation depends on some basic elements like the individual's former experiences, attitude at the time of the incident and sense of the threat to their well-being. Signifying the connection between the insidious post-traumatic stress disorder and personality, Judith Herman asserts that personality alters after repeated traumatic experience. She suggests that those who suffer from prolonged, repeated oppression and abuses become chronically traumatized people 
and their trauma is much more complex. According to her, chronically traumatized people are victims of personality disorder and are no longer healthy people. What would happen to African Americans' minds when they have been subjected to abusive treatments and psychological domination under the control of racist societies through generation? Their trauma would be distinct and differs from the outcome of a single traumatic event. It seems that their trauma is the prolonged repeated one and has its roots in the early beginning of slavery institution and continues to the present America. Therefore, the symptoms of personality disorder diagnosed in the victims of traumatic events might appear in African American men as well.

\section{1- Conce ptual The ory}

Based on an extensive accumulating research and studies on the impression of trauma on women, children and Holocaust victims' conditions, the American psychiatrist, Judith Herman, produced her precious book Trauma and Recovery in 2001 in which she differentiates between the two forms of traumatic events: the single and the prolonged repeated traumas. The single traumatic event might take place anywhere while the prolonged, recurrent trauma is only found in conditions of 'captivity' as the victim has no way for escaping and is dominated by a perpetrator. This fact makes Herman's concept relevant for this study, although she does not specify the trauma of African Americans as the main focus in her study is women's prolonged trauma.

\section{2-1 Psychological Domination}

Based on previous studies, records, and testimonies of victims from different life spheres like hostages, prisoners, and women whether in domestic area or pornography, it is proven that the employed techniques used by one person to subjugate another are noticeably consistent everywhere. Herman affirms that techniques of psychological domination are established on "the systematic, repetitive infliction of psychological trauma" (77). These techniques are embraced by what is called coercive control whose psychological influences have common features with subordination methods including the methods of 'disempowerment' along with 'disconnection'. Generally, by the techniques of psychological domination, it will be almost possible to produce fearful, vulnerable, and emotionally broken people.

In order to instil fear, the abuser usually attempts to assault the victim's sense of freedom. The perpetrator exerts an absolute domination over every detail of the victim's everyday life which is attained by confining the victim's physical needs. Herman emphasises that these damages of self and physical autonomy reflect in the destruction of the victim's world assumption and norms of behaviours. In addition, this destruction in sense of autonomy in Herman's terms "shames and demoralizes" the victim. (77) This technique also a ims to induce fear and justify the perpetrator's godlike power. Direct threat of death or serious harm, violence, and force to witness others distress or violent deaths are common techniques of fear to get its task accomplished. To achieve an ultimate control over the victim, the perpetrator attempts to destroy their attachments along with their self-image in relation to others. Shattering the victim's unity whether with family, friends or/and community, along with material support like information and education lead the person to be dependent and make the perpetrator's power boundless. Consequently, the victim 
becomes confident that any form of resistance is doomed to failure, and as the safest choice, gaining sympathy is achieved by ultimate obedience.

Total surrender, Herman affirms, is the final and the most psychologically destructive of all coercive techniques. In this final technique of control, the victim is rendered 'broken'. Herman recognizes two phases in this course of psychologically breaking of the victim. The first is achieved when the victim goes through a state of "robotization"; which means a shutdown of emotions, anticipation, verdict, and initiative. It is also achieved when the victim is enforced to witness helplessly the brutality against their close relatives. The second stage of breaking down in the victim's psychological state is completed when "the victim loses the will to live" (85). This loss of will to life differs from the will to committing suicide. While the latter is perceived as a sign of pride and resistance, the former is viewed to be the ultimate phase of approving an approach of complete 'passivity'. In this stage, the survivor does not show any endeavour for finding supplement, rest, food, and does not even avoid being beaten; turning into a state of 'living dead'.

\section{2-3 The Syndrome of Chronic Trauma}

Post-traumatic stress disorder and complex post-traumatic stress disorder have the same categorical symptoms of hyper-arousal, intrusion and constriction. Yet, these symptoms are amplifying in survivors of complex post-traumatic stress disorder and interfere with some other psychological problems which are developed as a direct result of the repeated form of the traumatic events.

According to Herman, the hyper-arousal state occurs when the person's system of self-protection becomes vigilant, as if the threat would reoccur at any instant. In this state the traumatized victim "startles easily, reacts irritably to small provocations and sleeps poorly" (35). The recurrence of trauma strengthens the hyper-arousal symptom of post-traumatic stress disorder; therefore, chronically traumatized person is frequently hyper-alert, restless and nervous. Consequently, they suffer from anxiety in addition to collapse of bodily health that it results in somatic problem. Intrusion is a period after the traumatic event which is experienced by the survivors as they recall the traumatic moments repeatedly as if it was taking place again. Due to intrusion which persists for a long time, the traumatized individual becomes unable to continue normally the passage of their life:

It is as if time stops at the moment of trauma. The traumatic moment becomes encoded in an abnormal form of memory, which breaks spontaneously into consciousness, both as flashbacks during waking states and as traumatic nightmares during sleep. Small, seemingly insignificant reminders can also evoke these memories, which often return with all the vividness and emotional force of the original event (Herman, 37).

Herman asserts that the traumatic memory is different from the ordinary memory in a variety of unusual qualities. It seems to be congealed, wordless and "encoded in the form of vivid sensations and images" (38). The reason behind these qualities is the fact that they are not comparably programmed into the usual memories of human being in "a verbal, linear narrative that assimilated into an ongoing life story" (37).

Reliving the trauma is described by Freud as 'repetition compulsion' Herman reassuringly comments that the traumatized person desires to "assimilate" and "liquidate" the traumatic event. 
The traumatic event, when occurs, destroys the ability of healthy "inner schemata". The disintegrated traumatic experiences are kept in a particular sort of "active memory" that has an intrinsic inclination to "repeat the representation of contents" (Herman 41). The extreme responsive agonies that accompany recurrence of the trauma make the victim attempt to avoid it. She asserts that the struggle to protect oneself from the intrusion symptoms worsens 'the posttraumatic syndrome', because this effort for avoidance causes "a narrowing of consciousness, a withdrawal from engagement with others, and an impoverished life" (42).

The constriction symptom is expressed by Herman as a factor which comprises the victim's changing into an absolutely powerless and surrendered person. This symptom is shown when the person's self-protection mechanism shuts down. Thus, when there is no way for physical escape, the victim shifts her state of consciousness. In fact, the constriction symptom is overstressed in victims of chronic repeated trauma. The dehumanization and the degradation that the abused person goes through along with the psychosomatic limitations become a vital form of adaptation which "applies to every aspect of life - to relationships, activities, thoughts, memory, emotions, and even sensation" (87). The victims become skilful practitioners of "dissociation, voluntary thought suppression, minimization, and sometimes outright denial" (ibid). Herman addresses this psychological alteration as "doublethink" and defines it in Orwell's term:

"Doublethink means the power of holding two contradictory beliefs in one's mind simultaneously, and accepting both of them. The [person] knows in which direction his memories must be altered; he therefore knows that he is playing tricks with reality; but by the exercise of doublethink he also satisfies himself that reality is not violated. The process has to be conscious, or it would not be carried out with sufficient precision, but it also has to be unconscious, or it would bring with it a feeling of falsity. ... Even in using the word doublethink it is necessary to exercise doublethink (Herman, 87).

Another type of alteration acquired by the person in captivity is 'trance' ability'. Herman confirms that this ability is normally found in a very 'hypnotizable' person, by which the traumatized victim dissociate his internal self into two separate personalities, the positive and the negative ones, creating a sort of conversation between them through hallucinations. Although these methods of alteration seems to help the chronically traumatized survivors to avoid the intrusion symptom, its effects develop later to influence on more aspects.

Moreover, the psychological constriction goes further in the survivors developing their abilities, willingly, to limit and suppress their confidence in future other than in the past. The thought of future provokes such a profound longing and pessimism that individuals perceive it as unbearable feelings which render them helpless and disillusioned. Besides, any thought about the past becomes painful and nostalgic due to the extreme coercion methods. Thus, since they normally lose their sense of connection with the past as well as the future, the traumatized person ruptures between present and past, which continues even after releasing from captivity. Herman sums up that accordingly "the chronic trauma of captivity cannot be integrated into the person's ongoing life story" (89). For the most survivors of chronic trauma, talking about their story with others is not something likable. The more these stories are denied, the more they repeat themselves through intrusion symptom. Besides the changes in the sense of time, there is a limitation of active engagement and determination which makes the traumatized person appear as a passive or helpless subject in which can be seen as the victim's alternative way for survival. 
The influence of chronic trauma normally extends to great lengths to break down and alternate the victim's psychological self-structure, and 'identity'. These alteration of self and identity cannot be assumed after being free from the bondage. The new identity after release forcefully includes the memory of their former subjugated self. Their image of themselves in relation to others must be based on the one who can lose and be lost to others. The product, for most survivors, is "contaminated identity" bringing about anxiety along with shame, detachment, "selfloathing' and a sense of failure. Herman perceives that "alterations of personal identity were a constant feature of the survivor syndrome" (94). As a result of all psychological alterations of the self, the victim, more probably, loses the basic principle of faith. Most of them create the sense that they have been betrayed or forsaken by God as passing through and observing the atrocities or subjugations.

Based on various studies, the series of the psychological losses create a persistent condition of depression which is the utmost mutual syndrome of chronically traumatized people. The prolonged hyper-arousal and intrusive symptoms of post-traumatic stress disorder mingle with the somatic symptoms of depression, creating "survivor triad" of insomnia, nightmares, and psychosomatic complaints. The separate symptoms of the disorder join the 'concentration' problems of depression like the loss of hope, difficulty of holding any healthy relationship, alienation as well as sense of shame and guilt. Herman affirms that survivors of prolonged repeated trauma produce severe psychological damages, growing an inner problematic type of post-traumatic stress disorder that attacks and destroys the 'personality'. The features of this complicated trauma differ from any ordinary emotional disorder; Herman asserts "[t]heir depression is not the same as ordinary depression. And the degradation of the ir identity and relational life is not the same as ordinary personality disorder" (118). The currently outlined diagnos is of 'post-traumatic stress disorder' proved to be inadequate for describing the symptoms of prolonged repeated trauma as it seems to be 'far more complex'. Survivors of captivity induce features of "personality changes, including deformations of relatedness and identity" (119). In the same manner, survivors of maltreated and neglected childhood become subject to the same kind of symptoms with connections and personality, and they remain principally helpless. Herman labels the syndrome that results from prolonged repeated trauma as "complex post-traumatic stress disorder" (C-PTSD).

\section{2- Analysis}

\section{3-1 The Ele ments of Frank's Psychological Domination}

Frank Money's psychological trauma is a prolonged one in form since its starting point is unrecognizable due to his ancestral trauma, what Leary terms as "a legacy of trauma" (121). As the son of a poor family, Frank Money tries to survive the difficulties in the town of Lotus, Georgia in South America during 1940s-1950s.

\section{3-1-a Ins titutionalizing Domination}

Throughout the course of his childhood, he experiences lots of traumatic events that render him psychologically dominated. Frank comments that living in Lotus, "[a]ny kid who had a mind would lose it" (84). As a child, he is the victim of violence, abuse and threat which keep him in a state of constant fear. He witnesses the destruction of their home when the whites expel them 
from Texas, "living in your own house for years, and still, men with or without badges but always with guns could force you, your family, your neighbours to pack up and move - with or without shoes....'Else' meaning 'die"' (9-10). Frank's parents have to work (as any black in America 1930-1950s) "from sunrise until dark" (43); therefore, they are "beat by the time they came home" (52). When the parent is at work, Frank and his sister become the target of the abusive treatments of the step-grandmother, Lenore, who repeatedly instilled panic and intimidated them. She frequently batters them and threatens them to lie on the "stripes and welts on their legs" (44). As a result, Frank develops feelings of isolation and betrayal that destroy his relation with his parents. Verdelle describes African Americans parenting in the South during the era after the Civil War (1865) on ward as "broken, disappeared and diminished into helplessness themselves" (11).

Frank is rendered helpless due to the lack of roots, financial support and parental attention and protection. Frank's childhood environment was not suitable for producing a healthy psychological person. He remembers his daily life as he, hungry and barefoot, walked around eating, if available, "trash from the garbage cans", or waiting in line for the food donated by churches (40). He starts looking for a secure and warm place like home. He develops a sense of 'abandonment' which is a noticeable subject in Morrison's works of fiction. During one of his quests, Frank and his sister witness a traumatic incident of the violent murder and hasty burial of a black man. Frighteningly Frank goes home to sooth himself and escape the terror of this disgusting scene, but he disappointedly fails to attract the adults' attention, 'the grown-ups did not notice us. Some disturbance had their attention" (5). As a result, Frank suffers from what Herman calls 'protective failure' which is experienced at a mark of indifference and as a complicit betrayal. Rich confirms that when the child victim experiences trauma in form of abusive treatments or negligence from family and community, witnessing violence against his parents, or being a subject of community violence, he develops a sense of humiliation and shame for seeking help.

When the traumatized child, Frank, grows up his condition does not change, but, in fact, it worsens and even cannot find a job or improve his own situation. The imposed poverty deprived him of an intimate relationship with his parents who die out of poverty. He also has no source of know ledge and education since there are no schools in Lotus, apart from one church-school for girls with very poor inadequate materials. Being quite deprived of any subject of importance, Frank's self-image is destroyed along with his image of connection with others. He becomes completely isolated, internally and externally fragmented. He comes to convince himself that his perpetrator (segregated America) is all-powerful and there is no any potentiality for resistance because "he knew that being out-side wasn't necessary for legal or illegal disruption" (Morrison, 9). Therefore, Frank tries to win his dominator's indulgence (in form of money and self-esteem) through complete submission by joining, with both of only friends, the newly united army. Frank describes his hometown as:

Lotus, Georgia, is the worst place in the world, worse than any battlefield. At least on the field there is a goal, excitement, daring, and some chance of winning along with many chances of losing. Death is a sure thing but life is just as certain. Problem is you can't know in advance. In Lotus you did know in advance since there was no future, just long stretches of killing time. 
There was no goal other than breathing, nothing to win and, save for somebody else's quiet death, nothing to survive or worth surviving for (Morrison, 83).

Frank finds the army as the only solution for his misery; an opportunity to involve himself in a white society. Verdelle affirms that joining the army is appropriate since "a soldier, chances are good that you will lose the life you gain" (11), he has no choices for a respectable life and material resources. Yet, in joining the army, he leaves Cee, his younger sister, who does not have anyone else to rely on. Hence, Cee passes through her own portions of difficulties as a black female in America. So, complete domination upon Frank is achieved through the destruction of all required attachments for maintaining any human relation, thus, he has been already traumatized when he joins the army.

\section{3-1- b Combat Veteran at Korean War}

Frank's participation in war renders him totally broken. His fear is increased under the serious and violent threats of harm or annihilation in the war which is one of the major factors for rising post-traumatic stress disorder. In addition, he also witnesses the death of his best friends, Mike and Stuff which aggravates his problematic mental situation. Morrison describes the scene of Mike's death in a very effective manner:

Mike in his arms again thrashing, jerking, while Frank yelled at him. "Stay here, man. Come on. Stay with me." Then whispering, "P lease, please."... "Smart, Smart. Don't tell Mama." By the time medics got there, the urine on Mike's pants had frozen and Frank had had to beat away pairs of black birds, aggressive as bombers, from his friend's body. It changed him. What died in his arms gave a grotesque life to his childhood. They were Lotus boys who had known each other before they were toilet-trained, fled Texas the same way (Morrison, 97-98).

$\mathrm{He}$ is also helplessly forced to observe the agony and death of Stuff who has lost his arm twenty feet away from his body and finally dies on the stretcher "holding his severed arm in the connected one" (99). The severity of the scene confounds Frank and leads him to the stage of breaking. Herman's two stated stages of breaking down of the person into total surrender are proven in Frank's condition; firstly, when he "violate[s] his moral principal" by becoming a murderer at war and secondly, when he "loses the will to live" (Herman, 83-84). When Frank, outrageously and recklessly, starts firing skirting the broken parts of men, he is no longer worried about death. In fact, life for him ended with the death of his friends. In spite of Morrison's previous assertion that Frank was not 'brave' and even he used to feel "nervous after a kill" (98), he hopes for a more active life in army. This paradox reduces him to an absolute passive traumatized person, helplessly locked in the mental ward of a hospital.

\section{3-1-c Re-veteran at America's Segre gation War}

Back home, Frank thinks that he would be able to acquire some of the benefits of his own sacrifices and bravery and share the fruits of victory with American society; however, traumatically, he finds no less disrespect along with physical and psychological abuses. Frank's shoeless childhood journey once more takes place but this time he escapes from the hospital to save his sister who becomes a victim for a doctor's medical experiments. Throughout his quest, Frank encounters with lots of incidents that take Herman's concept of prolonged repeated trauma into consideration and associate it with the social suppression of African Americans under the whites' supremacy in America. Schreiber argues that "[r]ejection through separation perpetuates 
trauma" (4). Frank still has no access to most of the public services, for instance he cannot use the toilet when he needs, it is happened to him in one of the stations obliging him to relieve "himself in the shrubbery behind the station" (Morrison 23). This elimination from the mainstream resources can be compared to the condition of psychological domination Herman mentions in about the destruction of "the victim's sense of autonomy" (77). He cannot provide an accommodation for himse lf due to his poverty. Therefore, as a war veteran, Frank is deprived of material resources as well as of any shielding mechanism that would provide him with self-value. This deprivation can be seen as the control of physical debilitation.

Frank is kept in an irreversible horror by the threat of becoming what Leary describes as "human laboratory animals". African Americans' fear is instilled by this serious threatening condition and tragic situation. United States permitted to "run medical experiments on African Americans from 1932 through 1972” called Tuskegee (Leary, 98). In fact, Cee, Frank's only sister, becomes one of these experimental victims. But Morrison takes a further step to include the dead bodies of African Americans; as the pastor who gives aid to scared Frank "[y]ou lucky, Mr. Money. They sell a lot of bodies out of there...doctors need to work on the dead poor so they can help the live rich" (12). Thus, legal or illegal, alive or dead, they have no other ways around. The repeated forms of traumatic events render Frank to think about the means of survival rather than those of escape. His bodily system of self-defence becomes totally overwhelmed by the prolonged form of stress.

Frank experiences and witnesses the physical and the psychological assaults of the overriding whites which humiliate and demoralize him. Morrison highlights Frank's condition, after fighting for his country, saying "go fight, come back, they treat you like dogs. Change that. They treat dogs better" (18). He starts a journey to Georgia to save his gravely ill sister who becomes a victim of the medical experiment of an abusive doctor. Throughout his quests he passes through the terrors and abuses of racism in America. He becomes aware that all of his sacrifices and efforts to save his country in the war have been thrown away and he is still being looked down as a nigger. Once a policemen, in the ir random search, attack and dehumanize him by pushing him towards the wall and patting his pockets, the shame overcomes and he can no more talk about it with Billy, so they "walked off in silence" (37). In an occasion he is overwhelmed by the violent attack on a black couple. The man wants to have a cup of coffee from a white shop but the owner and his customers beat him brutally and even hit his wife as well, when she is trying to help her man (25). The scene shows a dreadful humiliation, not only for the husband but also for Frank as a witness, saying:

He will beat her when they get home... It's one thing to be publicly humiliated. A man could move on from that. What was intolerable was the witness of a woman, a wife, who not only saw it, but had dared to try to rescue -rescue!-him. He couldn't protect himself and he couldn't protect her either, as the rock in her face proved (Morrison, 26).

These violent incidents stick in his mind and become traumatic moments for him. During the antebellum era these demoralizations and abuses legally-allowed, however; in spite of their apparent abolishment, these abuses are shown in the public. Hence, witnessing various forms of abuses provide Frank with a negative image about being black in the mainstream white society. 


\section{3-2 Frank's Syndromes of Chronic Trauma}

Frank is frequently confronted with all of the stressors that each, according to according to Judith Herman's concept, is sufficient to warrantee chronic trauma. So far, it becomes obvious that Frank's psychological trauma is not only the result of the negative impacts of war, but also has its roots in his early childhood and he carries it into his adulthood. Herman emphasizes that there are two important factors in determining the forms of the disorder: the nature of the traumatic event and "individual differences" (58). In Frank's case, the nature of the events he has been exposed to extends from a single overwhelming traumatic event to the further form of prolonged repeated one. Conforming to the second point, being a black in a dominant white society in the 1940s-1950s America is sufficient to determine which kind of individual he is. Frank, as explained earlier, has a long history of pre-existing difficulties and, apparently, he is not a fortunate person to have any familial or social support for his stressors. Yet, the only social support he has been given is being handcuffed in the backseat of a patrol car, dragged, and thrown in a mental hospital. Frank eventually becomes a victim of chronic trauma whose negative impact is aggravated by the post-traumatic stress disorder he got from the war. Consequently, his trauma takes the form of chronic trauma whose syndromes are explained below.

\section{3-2-a Loss of Volume Control}

As a victim of prolonged, repeated abuse, Frank always lives in the fear of the repetition of the moments of terror or threat. He connects each present incident, even the one remotely or hardly related to violence, to a threatening past event. For instance when he wants to knock the reverend's door he is cautious and thinks his hand is hard in doing so "but not threatening like the bam-bam of a citizens' group, or a mob or the police" (11). His mind gets triggered with every new experience that happens to him. Beholding the police car, although he is not followed by, provides him with extreme anxiety. He becomes so over-sensitive with noise that in one situation he cannot stand the normal noise of the station because it is "so abrasive... so he leaned against a steel support until the panic died down" (27). Herman asserts that a traumatized person who suffers from a group of "generalized anxiety symptoms and specific fears does not have a normal 'baseline' level of alert but relaxed attention" (36). Frank shows reactions during his sleep and struggles to have a peaceful relaxing sleep. However, he loses control over his startled reactions which develop to the extent of removing his sense of safety.

The extensive and persistent arousal of Frank's autonomic nervous system shatters his 'fight or flight' response to an explosively aggressive behaviour. In this regard, Bloom refers to the 'fight or flight' response as the substantial response that the body creates every time it perceives any danger. When any person is exposed to threatening conditions repeatedly, they change dramatically to include every part of key organic functions. Consequently, the person, in many ways, becomes asymmetrical when he is frightened as well as when he is calm (3). In certain situations like the one in Korea, after the death of his friends, he began killing violently not just soldiers but even pedestrian civilians including women, children, and old men. There is a poor scavenging young girl that "he blows her away" (95) all of a sudden. He addresses his guard, the self-protective system or as is known 'fight or flight mechanism, 'he'; the third person, which means it is neither me (Frank) nor you (Morrison). Yet, it is 'he', someone he is not familiar with 
but has come to dwell inside him. Frank's body seems to be always vigilant for threat. Accordingly, Frank is not himself when he does any violent reaction, in particular, when he attacks the 'big man' who moves toward him as he is watching the fight between the two women. He enjoys the beating but cannot get over his distress and is "unable to stop and unwilling to" (101). Now, the fight for him is the opposite of flight; he realizes that it is different when saying "those sprees were fierce but mindless, anonymous" (102). Henceforth, Frank becomes the subject of emotional dysregulation; unable to control his mood response when he comes upon any form of incident that provokes an insecure feeling.

\section{3-2-b Compulsive Repetition}

Since Frank's trauma is a chronic form, his intrusive symptoms persist in form of flashbacks in nightmares, daydreams and the extreme reminders of his childhood experiences. Throughout the novel there is nothing new or optimistic in his life except the repetitive forms of traumatic experiences. His intrusive symptoms have profound roots as long as the repeated and prolonged nature of his trauma; consequently, they disturb him as he is awake in the form of movie slides. Even Morrison uses the term 'case' at different occasion, in Home, to describe Frank's state which might be suggesting that there is an issue needed to be studied as a mental case. Frank's case in any surrounding and at any time reflects the vision of:

[A] boy pushing his entrails back in, holding them in his palms like a fortune-teller's globe shattering with bad news; or he heard a boy with only the bottom half of his face intact, the lips calling mama. And he was stepping over them, around them, to stay alive, to keep his own face from dissolving, his own colorful guts under that oh-so-thin sheet of flesh. Against the black and white of that winter landscape, blood red took center stage. They never went away, these pictures (Morrison, 20).

These repetitions of the traumatic events, according to Caruth, are delayed and uncontrolled responses to the overwhelming experiences and they are central images for trauma symptoms (10). Herman also confirms that the intrusive symptoms in a chronically traumatized person are so severe and persistent that even lasts for forty years after the actual experience in some of her patients' cases. Frank has been haunted by the images which are ready to show themselves before his eyes all the time. He cannot turn off the movie screen showing the image of the injured and echoing their scream in front of his eyes. These intensely imprinted images are much powerful than the ordinary daily memories.

Frank has difficulty in recommencing a normal continuous life since it is constantly interrupting and breaking his normal development. All of a sudden, the scene in front of him becomes dried and colourless rendering him to doubt his own saneness and permanency, "he wondered if this was how dogs or cats or wolves saw the world. Or was he becoming color-blind?" (23). This incident in Frank's life is emphasised by Caruth as she said that the repetition of traumatic flashback effects the biological construction of the brain and can eventually cause 'deterioration'; it is life threatening (63). Frank cannot find a moment of rest out of flashbacks. With each recurrent moment of trauma, he shows a reaction to the actual events, for instance in occasion when he notices the small girl's smile in the church convention he suddenly becomes flooded with the same sense of horror and anxiety which makes him drop his plate, run away leaving Lily behind and later becomes beaten up by inexpressible shame. Still, he cannot find a verbal form 
for his memory; he is unable to express it to Lily while he is unaware of the reason behind its reoccurrence. When Lily asks whether his behaviour has anything to do with his time in Korea, he wonders "[m]y time?" (77). It is obvious that Frank's life is haunted by his trauma which conforms to Freud's labelled case 'trauma fixation' (Herman, 36).

Like the incongruous events in his life, Frank's traumatic memory and dreams are unordinary. $\mathrm{He}$ seems to be unable to put his memory into words or in a linear form; rather it appears in shape of commotion, buzz and pictures. For example Frank cannot remember why his face is bleeding when the pastor asks him during taking refuge at his house. Frank tries to remember; yet, what he remembers is "just the noise. Loud. Real loud" (13). There is no wholeness in the images he encounters with in his memory. They are always fragmented like legs, fingers, parts of face, and the half of human's body. Sometimes he hears sounds and the roar of guns or "squeeze of a trigger from a gun minus ammo" (33). The vision of the 'zoot-suited' small man appears to him occasionally, but silently. Consequently, Frank tries to interpret the images since he supposes they may attempt to convey messages. Frank's suffering with these wordless and blaring images that refuse to go away becomes problematic for achieving a continuous normal life he desires.

The prolonged traumatic experience has destroyed all Frank's self-structures including his own and others' self-image and self-esteem. His negative image of himself as a worthless being is aggravated by the social agreement of his inferiority. This vacant-esteem is influenced by three major factors as Leary categorizes: society, community and family (129). As Frank has been a subject for the disgraced and brutalized laws and codes of racial segregated America before and during 1950s, his perception of himself influences his self-valuation. Furthermore, the family's impact on his self-evaluation also has a great role as they themselves have lost theirs in the same manner or much worse. Finally, the community's influence on Frank's creation of self-worth has been shown through providing and assigning his limited role as either a field labour or a soldier. Schreiber points out that in accordance with the impact of white community on the black's selfimage, "the white construction of black subjectivity produces chronic trauma for black Americans, generated by being defined as other by a racially exclusive larger culture" (3). These negative images and depictions have rendered Frank humiliated and shattered. Moreover, the feeling of inferiority fills him with shame and doubt. These feelings are shown in the eyes of Billy's son when Frank asks him about his plan for future career and he replies to be "[a] man" (33). His purpose of being alive is shuddered and disturbed; he ultimately has no goal for future, "selflessness without gain or emotional goal" (35).

Accordingly, Frank's basic assumptions about the world and faith propel him to a state of 'existential crisis'. In an instance, he even questions the divinity order of the world, "[t]he sun did her best to burn away the blessed peace found under the wide old trees; did her best to ruin the pleasure of being among those who do not want to degrade or destroy you" (118). His assumptions about the basic trust in God is shaken when he hears his friends, crying and calling for God are not answered, "Jesus. Jesus!" That's what Mike said. Stuff yelled it too. "Jesus, God Almighty, I'm fucked, Frank, Jesus, help me" (31). He comes to believe that his "life is rougher than confronting a battlefield" (109); thus, being violent might warrantee staying alive in such a society. However, his prolonged fear covers his will of being violent when he saved his sister. After all of his losses, Frank feels completely abandoned, completely isolated, and removed from human blissful and celestial protective communities. 


\section{3-2-c Dissociation}

To escape from his unbearable reality, Frank employs the psychological constriction as a means of creating safe device. Frank, consciously, practices the art of altering consciousness by supressing and denying both of his overwhelming experiences along with his feelings about them. It seems that the whole structure of the novel is based on the concept of 'doublethink'. Home for the most part is written in the third person; yet, it is interposed with italic script printed chapters in which its 'I' denotes that the speaker is Frank and he is talking to someone, anonymous who is writing his story. In her study on some women prisoners, Herman explains that they regularly create affirmative and negative 'hallucinations' and separate parts of their personality (88). Therefore, it can be assumed that it is Frank who is talking during the whole novel but with shifted personality. What is important here is that he tries to suppress and deny one of those parts, for instance in different occasions, he attempts to conceal the fact that he is the one who killed the Korean child, and in the other part he admits his crime and confesses that he lied "to you and I lied to me. I hid it from you because I hid it from me. I felt so proud grieving over my dead friends. How I loved them. How much I cared about them, missed them. My mourning was so thick it completely covered my shame" (Morrison 133). As a result, within the whole novel, he is simultaneously able to hold two contradictory ideas and feelings of mourning and proud.

One more dissociation technique used by Frank is altering his perceptions and thoughts. His practice of the technique of 'trance state' is admitted by Morrison:

[T] he trick of imitating semi-coma, like playing dead facedown in a muddy battlefield, was to concentrate on a single neutral object. Something that would smother any random hint of life. Ice, he thought, a cube of it, an icicle, an ice-crusted pond, or a frosted landscape. No. Too much emotion attached to frozen hills. Fire, then? Never. Too active. He would need something that stirred no feelings, encouraged no memory - sweet or shameful (Morrison, 7).

This technique becomes habitual for Frank especially after the embarrassing incidents of the church convention. The smiling little girl in the church reminds him of the scavenging girl he killed in Korea; so, he starts dissociating his thought from his experience. He realizes that he must avoid his wordless manifestation of that feeling instead of displaying it in order not to cause embarrassing situations for Lily. He almost passes through moments of pure silence while he is "numb, unwilling to talk" (Morrison 21). Subsequently, the constriction methods limit his capability of active engagement with the world. He loses the job he has difficultly got and he frequently stands helplessly while Lily is having difficulties in handling household responsibilities. Reyes asserts that due to the severity of the constriction symptoms for victims of chronic trauma, they constantly feel disagreeably disordered, chaotic, and bewildered losing the concentration which renders them overwhelmingly incapable of governing their own actions, minds and bodies (153). Therefore, Frank becomes completely irresponsible for major or small necessities of daily life and Lily has to take his responsibilities disappointedly.

Trauma, in many ways, disrupts and disorders Frank's basic relational life. The only profound connection in his life is with his sister. Since he, for the psychological purposes, espouses to Lily, he is not able to sustain both relationships. His sister is disappointed by her brother's irresponsibility since "she thought, of having a smart, tough brother close at hand to take care of 
and protect [her]" (48). In the same way, "[t]he fog of displeasure surrounding Lily thickened. Her resentment was justified by his clear indifference, along with his combination of need and irresponsibility. Their bed work, once so downright good to a young woman who had known no other, became a duty" (79). In a different occasion, Cee acknowledges that Frank, although sheltered her, did not 'strengthen' her; he only literally saved her. It seems that Frank becomes indecisive between deep attachments and frightened withdrawals; he approaches and admits his need for such closeness, then he realizes that he is not suitable for his roles and withdrawing is his alternative way. Consequently, he is left with a permanent sense of alienation, disconnection and isolation.

In Frank's case, the two intense symptoms of constriction which appear in the form of avoidance and numbness along with intrusions like flashback and nightmares comprise a persistent state of depression. The stressors, over the series of losses and detachments in Frank's life, develop a severe depression that makes him lose control and become sleepless. Reyes observes that the stressor of the depression of a person whose prolonged trauma combines with PTSD, manifests itself in a various fields including occupation, connections to others and bodily health (197). The sign of Frank's depression is obvious in every aspect of his traumatic experience like his sudden outburst into cry and violence. He attempts to regulate his inner psychological state and demolish his sense of guilt by drinking alcohol. He directs all of the suppressed rages against his oppressors and those who seemed to be unresponsive to his troubles to himself. At the end of the novel Morrison describes his state as being unable to have rest or sleep:

[E]ntangled in thoughts relentless and troubling. How he had covered his guilt and shame with big-time mourning for his dead buddies. Day and night he had held on to that suffering because it let him off the hook, kept the Korean child hidden. Now the hook was deep inside his chest and nothing would dislodge it (Morrison, 135).

Hence, Frank remains typically loose, jobless, and unable to keep his mind quiet.

\section{3-3 A Further Aura of C-PTSD}

It has been perceived in this research that besides distracting the victim's identity, chronic trauma and complex post-traumatic stress disorder embraces the experience of disruption of one's own gender as well. It is contended and agreed that gender is not determined by individual's biology rather it is acquired, learned and socially constructed regardless of gender identification. This study claims that gender construction might be effected by external and internal influences pertaining to trauma. Most of the studies on African Americans' traumatic experiences have emphasised upon individual features paying little attention to further social influences, particularly to the social construction of masculinity and manhood. As mentioned before, Herman's theory of C-PTSD concerns with women's traumatic experiences of rape, domestic violence, and abuse. Since femininity, as masculinity, is something socially constructed, acquired and performed, Herman's theory, dealing with gender-penetrating approaches to trauma, is applicable to men's traumatic experiences and reactions as well. This study argues that complex post-traumatic stress disorder disrupts man's sense of masculinity.

Numerous common features of masculinity are noticed amongst a variety of discourses. The matter of independence, autonomy and demonstrating manliness by dominance and power, even if it implicates a violent act, are the primary features. Here, being aggressive and violent is 
considered as an advantage and as a manly open investigation of masculinity (Fox and Pease, 20). The traditional western discourse considers masculine individuals "to be strong (physically powerful and emotionally stoic)" (Tyson, 87). Hence, it is not proper for them to show any sign of weakness including showing fear, pain or crying resulting from being overcome by their emotions demonstrating a sign of unmanliness. Furthermore, a man's failure in any sphere of life suggests the failure in his manhood. For Tyson, the most demeaning failure for a man is when he does not provide acceptable financial support for his family "because it means that he has failed at what is considered his biological role as provider" (87).

Considering the distinction between the traditional gender roles of masculinity and those of femininity is principally significant in this context since trauma experience have been regarded as a feminine experience. A man, experiencing personality disorder, is perceived to be inadequate for his social role, and in some cases exhibits feminine traits involving in embarrassing experiences. C-PTSD presents a trauma that is remarkable and overwhelming; a trauma that is not expected to be tolerantly dealt with since it is out of the victim's will and beyond his capacity. Likewise, by highlighting the uniqueness of African Americans' experiences and CPTSD's relationship to it, this paper gives personality disorder a further aura through concentrating on male emasculating. Provided with the outlooks of traditional masculinity, complex post-traumatic stress disorder involves a loss of autonomy, disconnection from close relationship, altering ones world assumptions, loss of identity which is unattainable, and being rapt by passivity and restriction which all can be considered as a failure to masculinity. Moreover, since the basic condition for being a proper masculine individual is being physically and emotionally strong and since our male protagonist, Frank, ultimately becomes bodily and emotionally wrecked, he is outside the scope of manhood.

Frank is deprived of performing the role of a man. His psychological trauma destroys his ability as a 'protector' and 'provider'. He is aware of his failure in fulfilling his responsibility as a brother, but he is obliged to leave her, Cee, in order to find his manhood through joining the army. He has the same problem with his girlfriend Lily whom he dissatisfied as well. The intensity of the traumatic syndrome fills him with shame, guilt and disempowerment and finally leads him to cause embarrassing situations for Lily. While the traditional gender roles prioritize masculine personality, Frank possesses a weak and fragile personality. In fact, he lacks the important factor "considering its implications for solidarity and closeness" (Ickes, 76). He also is rendered helpless due to his numbness and dissociation syndrome which is revealed in his irresponsibility towards essential routines of everyday life like "unpaid bills, frequent gas leaks, mice, runs in her last pair of hose, hostile, quarrelling neighbours, dripping faucets, frivolous heating, street dogs, and the insane price of hamburger. None of these irritations did Frank take seriously" (Morrison, 75). He becomes so indifferent, disabled and dependent that Lily becomes totally disappointed with him. Moreover, the destruction of general assumptions makes him so hopeless and aimless that thickens the fog of displeasure surrounding Lily, especially when she feels "he shared none of her enthusiasm for achieving" (75). Consequently she does not see in him the man she can rely on.

Trauma leaves Frank emasculated rendering him feel guilty of disappointing his sister and not taking his expected brotherly personalities. In fact, the chronic syndromes of his trauma make him a helpless witness of his own damage as a man who cries "for a reason he did not 
understand" (Morrison 22). Crying, as mentioned earlier, is the primary sign of Frank's disempowerment and emasculation. He is no longer able to keep his job due to the severity of his syndrome which weakens his function and influence as a man. His physical and emotional breakdown denies his masculinity since virility, ambitiousness; combativeness, toughness; aggressiveness and competitiveness are essential traditional masculine features. Moreover, sexual desire is an accepted belief which distinguishes a male individual (Ball, 97). Frank attempts to be violent and aggressive in order to attain a part of his manliness; however, evidently, he fails when he encounters with the physician who did the medical experiment on his sister, and thickened with fear leaves calmly. It appears that the syndromes of chronic trauma leave Frank with the sense of malfunction and empty of self-confidence preventing him from fulfilling his responsibilities as a man, a lover, and a brother.

\section{3- Conclusion}

Taking into consideration the fact that after the Civil War in 1865 slavery is literally abolished and all slaves were supposedly became free, one may think that their trauma came to an end. Yet, the bitter story of discrimination and abuse has not ended. Although during 1940s-1950s, as presented in Morrison's Home, particular legal masters did not possess black slaves, African Americans were legally and illegally dominated by the whole white society. This research has argued and demonstrated that African Americans' trauma is not a simple and a classic trauma resulting from particular and single traumatic events. However, it is a chronic trauma which leads to what Herman recently labelled as the complex post-traumatic stress disorder caused by a prolonged, repeated trauma. Through the application of Herman's theory, this study aimed to prove that Herman's psychological trauma theory, centring on abused women and Holocaust survivors, is applicable to literature, her study can be broadened to include African Americans' traumatic experience in the United States as well.

It has been noticed that chronic trauma, through studying Frank Money's personality, leaves male African Americans in a puzzling state. However, it also subtly contradicts the value of the experience of being a veteran, for Frank, as it is established on a verified absence of those very qualities that, in traditional terms, outline a man. By not corresponding to the masculine ideals, complex post-traumatic stress disorder undertakes a pathology that challenges the aimed renewal of autonomy. In this regard, the problems recognized by Herman with concern to the experience of women seem likewise applicable to the case of male African Americans, like Frank in Morrison's Home. Moreover, the concepts lay beneath chronic trauma highlights that the previous personality counts on assumptions have been intensely dislocated through prolonged repeated trauma. Therefore, lots of African Americans' misunderstood behaviours can be justified through the findings of this study. The concepts underlying complex post-traumatic stress disorder signify that the extended roots of slavery still function so influentially that deprive male African Americans, Frank, of fulfilling the expectations and ideals of manhood and traditional masculinity. This research concept helps to highlight the profoundness of this catastrophe which devastates their self-image and confidence. In fact, complex post-traumatic stress disorder, as a psychological disease, places male African Americans in a new land without any road maps. In effect, the emasculation of African American men through depriving them of certain notions of manhood is the true humiliation of man. 


\section{References}

1. Ball, Durwood. "Cool to the End: Public Hangings and Western Manhood." Across the Great Divide: Cultures of Manhood in the American West. London: Routledge, 2001. 97-108.

2. Bloom, Sandra L. 2004 (1999). "Trauma Theory Abbreviated, Philadelphia, 1999. Community Works. <http://www.sanctuaryweb. "Bloom, Sandra Trauma Theory Abbreviated." From the Final Action Plan: A Coordinated Community Response to Family Violence.. Philadelphia: Community Works, 1999. 1-17.

3. Caruth, Cathy. Unclaimed Experience: Trauma, Narrative and History. London: JHU Press, 2010.

4. Herman, Judith Lewis. Trauma and Recovery. New York: Basic Books, 2001.

5. hooks, bell. We Real Cool: Black Men and Masculinity. New york : Routledge, 2004.

6. John Rich, Theodore Corbin, Sandra Bloom, Linda Rich, Solomon Evans, Ann Wilson. Healing the Hurt:Trauma-Informed Approaches to the Health of Boys and Young Men of Color. Drexel University : Center for Nonviolence and Social Justice and Department of Medicine, 2009.

7. Kinchin, David. A Guide to Psychological Debriefing: Managing Emotional Decompression and Post-Traumatic Stress Disorder. London: Jessica Kingsley Publishers, 2007.

8. Leary, Joy DeGruy. Post Traumatic Slave Syndrome: America's Legacy of Enduring Injury and Healing. Portland: OR: Joy DeGruy Publications, 2005.

9. Morrison, Toni. Home. New York: Random House Incorporated, 2013.

10. Reyes, Gilbert, Jon D Elhai and Julian D Ford. The Encyclopedia of Psychological Trauma. Hoboken, N.J.: Wiley, 2008.

11. Schreiber, Evelyn Jaffe. Race, trauma, and home in the novels of Toni Morrison. Baton Rouge: Louisiana State University Press, 2010.

12. Terr, L. Too Scared To Cry: Psychic Trauma in Childhood. New York: Harper and Row., 1990.

13. Tyson, Lois. critical theory today: A User-Friendly Guide. New York: Routledge, 2006.

14. Velsen, Cleo Van. "Theoretical models of post-traumatic: Psychoanalytical models." Dora Black, Martin Newman, Jean Harris-Hendrks, Gillian Mezey. Psychological Trauma: A Developmental Approach. London: Gaskell, 1997. 61-64. 